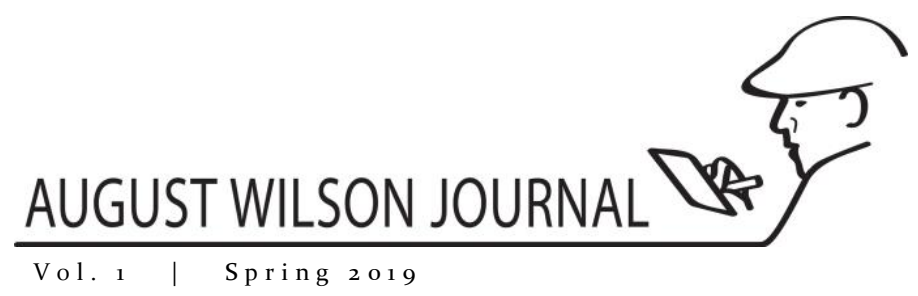

\title{
Erratum: Addington, Thomas. "Bibliography for August Wilson Journal: Spring 2019." August Wilson Journal doi:https://doi.org/10.5195/awj.2019.28.
}

\author{
Michael J. Downing
}

Editor

In Addington, Thomas. "Bibliography for August Wilson Journal: Spring 2019." August Wilson Journal doi:https://doi.org/10.5195/awj/2019.28, author "Thomas Addington" was changed to "Thom C. Addington." 